\title{
Time Preferences and Job Search: Evidence from France
}

\author{
Bassem BEN HALIMA - Mohamed Ali BEN HALIMA
}

\begin{abstract}
Increasing impatience reduces search efforts of unemployed job seekers and therefore decreases the exit rate from unemployment. Also, impatience reduces reservation wage and increases the exit rate. To determine the overall effect of impatience on the exit rate from unemployment, we distinguish between exponential and hyperbolic time preferences. Search effort dominates the reservation wage and decreases the exit rate from unemployment if individuals have hyperbolic, rather than exponential, preferences. Using the French sample of the European Household Panel Survey, we found that search effort has a strong effect on the duration of unemployment, whereas the reservation wage is not significant. This result shows that the job seekers have hyperbolic preferences. Hyperbolic preferences affect problems associated with job search and policies aimed at reducing unemployment.
\end{abstract}

Keywords : Time preference, Hyperbolic discounting, job search.

Classification JEL : D90, J64, C41

Bassem BEN HALIMA, Université Lumière Lyon 2, Groupe d'Analyse et de Théorie Economique, CNRS, UMR 5824, 93 Chemin des Mouilles - BP 167- 69130 Ecully - France. E-mail: bbenhalima@ gate.cnrs.fr.

Mohamed Ali BEN HALIMA, Centre d'Etudes de l'Emploi, Noisy-le-Grand, F93166 and Groupe d'Analyse et de Théorie Economique, CNRS, UMR 5824, Ecully, F-69130, France. E-mail: mohamedali.benhalima@cee.enpc.fr

We would like to thank Jean-Yves LESUEUR and an anonymous referee for their helpful comments. 


\section{Introduction}

Sequential models of job search make it possible to make predictions about the equilibrium of the influence of observable and unobservable individual characteristics on the exit rate from unemployment. In this literature, time preference is a significant factor, because it defines the level of the reservation wage as well as the intensity of the job search. We are interested in the observation, reported in many studies, of a great acceleration of the exit rate from unemployment near the completion date of unemployment benefits. This phenomenon may be taken an indication that unemployed workers have modified the conditions of their intertemporal trade-offs. However, in the literature on the modelling of time preference (Becker and Mulligan, 1997; Harris and Laibson, 2001), the effect of impatience on job seeking has attracted little attention in recent years, even though it is closely related to the theory of job search.

The investigation of the influence of time discounting on the equilibrium properties of models of job search, which view search effort as endogenous (Mortensen, 1986), generally does not reveal a determinate effect on the exit rate from unemployment. On the one hand, increased time discounting (impatience) ${ }^{1}$ leads an unemployed worker to attach little importance to the advantages of job search. Thus, the unemployed worker exerts little effort on job search. This behaviour tends to result in fewer job offers being received and to increase the duration of unemployment. On the other hand, increased time discounting also leads to a lower reservation wage and hence shortens the duration of unemployment. Impatient unemployed worker prefers to accept an offer of employment immediately, rather than wait for an additional period to receive a better offer. This effect tends to reduce the duration of unemployment and it is opposed to the effect of a fall of the intensity of search. This standard result, often cited in the specific literature, is due to the relatively simple modelling of the time consistency that is retained in the majority of the models. At the same time, an increasing 
number of researchers have been interested in testing the time consistency of agents, generally by conducting experiments in the laboratory, starting from exponential or hyperbolic discounting function (Laibson, 1997; O’Donoghue and Rabin, 1999; Cox and Oaxaca, 1989, 1992).

The Discounted Utility (DU) model (Samuelson, 1937), which is often used by economists, has received a modicum of support from empirical research. Empirical research on intertemporal choice has revealed that the DU model is inadequate as a descriptive model of behaviour in a number of respects. This model shows that an individual who has intertemporal preferences represented by an exponential discounting function makes consistent choices and that his preferences are never reversed, which implies a constant discount rate through time. However, the studies of Pender (1996) and Chapman (1996) show that discount rates are not constant over time, but appear to decline. This pattern often referred to as hyperbolic discounting. The term 'hyperbolic discounting' is often used to denote a decrease in impatience over time, with a high discount rate in the short run and a low one in the long run. The existence of this phenomenon has been confirmed by the studies of Myerson and Green (1995) and Kirby (1997) ${ }^{2}$. The hyperbolic discounting function contradicts the assumption of the time consistency of preferences (Fang and Silverman, 2004) and supports the decrease of impatience over time.

Hyperbolic time preferences have enormous implications for labour market policies. Hyperbolic worker is particularly sensitive to the immediate costs of the job search and seeks to reap the benefits of search quickly by accepting a job offer in the near future. Consequently, job-search programmes can help hyperbolic workers by finding a way to reduce the short-term costs of job search. It may also be possible to use interactive kiosks, where potential job applicants can submit their curriculum vitae and also schedule an interview at low cost to themselves. The interactive kiosks could coordinate between the 
various actors who help the applicant to gain employment. If costs represent a barrier for the search of hyperbolic job seekers, the availability of such interactive kiosks will encourage them to keep looking.

This paper reports on an empirical study of the effects of impatience on job search outcomes. The originality of this paper is to compare our results obtained from the French data with the results of Della-Vigna and Paserman (2005) on U.S. data. More impatient workers search less intensively and set a lower reservation wage. The effect of these tactics on the exit rate from unemployment is unclear. In their study, Della Vigna and Paserman (2005) distinguish between different types of time preference: exponential and hyperbolic. They also distinguish between short-run and long-run impatience. The search decision involves a tradeoff between immediate search costs and the future benefits of accepting an offer made within a few weeks. Over this limited time frame, variation in short-run impatience matters more than variation in long-run impatience. In contrast, the decision concerning the reservation wage involves comparing the long-term consequences of obtaining a certain wage or waiting to receive an even better offer. In this case, variation in long-term discounting is more significant than variation in short-term discounting. According to the exponential discounting model, job seekers are concerned more with long-run impatience than short-run impatience. In this case, the effect of the reservation wage will dominate the level of the search effort, because the decision on the reservation wage depends only on long-run impatience. Accordingly, job seekers who become more impatient tend to exit from unemployment more quickly, because they lower their reservation wage. On the other hand, according to the hyperbolic discounting model, job seekers are more prone to be impatient in the short run than in the long run. In this case, the effect of the search effort will dominate the level of the reservation wage, because the search decision depends only on short-run impatience. 
Therefore, job seekers who become more impatient tend to exit from unemployment more slowly, because they expend less effort on search.

Using the French sample of the European Household Panel Survey, we test these theoretical predictions empirically. We find that various measures of impatience are correlated negatively with search effort and the reservation wage. This result shows that when job seekers become more impatient, they tend to expend less effort on search and to lower the reservation wage. We also show that search effort has a strong effect on the exit rate from unemployment, whereas the effect of reservation wage is not significant. This result shows that individuals have hyperbolic preferences. Consequently, when they become more impatient, they exit from unemployment more slowly because they reduce the amount of effort on job search.

The remainder of the paper is organized as follows. Section 2 outlines the various assumptions made by the model of Della Vigna and Paserman (2005). In Section 3, we provide a descriptive analysis of the data, the choice of the impatience measures, and a nonparametric analysis of the effects of these measures on survival function in unemployment. In Section 4, we demonstrate the estimation and principal results. Section 5 concludes by summarizing the main results.

\section{The search model of Della Vigna and Paserman (2005)}

We now examine the various assumptions made by the model of Della Vigna and Paserman $(2005)^{3}$. In their model, search effort is endogenous ${ }^{4}$ and determines the probability of receiving a wage offer in any period. Hence, the job seeker expends search effort $s$, parameterized as the probability of obtaining a job offer. Therefore, $s \in(0,1)$. The probability of receiving a job offer during a sequence of searches is an increasing function of the intensity of search effort, but an increase in the search effort also augments the cost of the search. In 
each period, the job seeker incurs a cost of searching $c(s)$ with $c^{\prime}(s) \geq 0$ and $c(0)=0$. The job offer is characterized by a wage $w$. The structure of time preferences of Laibson (1997), Strotz (1956), Phelps and Pollak (1968), is used as a simplification of hyperbolic time preferences. Let $u\left(c_{t}\right)$ denote the stream of per period utility that is derived from consumption. The present value of a flow of future utilities at time $t$ is $u_{0}+\beta \sum_{t=1}^{T} \delta^{t} u_{t}$. $\beta \in(0,1)$ is a parameter that reflects short-run patience and $\delta$ is the discount factor that captures long-run patience. When $\beta=1$, the rate of time preferences is constant and preferences are time-consistent, which is the standard exponential discounting case. When $\beta \in(0,1)$, time preferences are quasi-hyperbolic ${ }^{5}$. The discount factor between the current period $t$ and the next one $t+1$ is $\beta \delta$, while the discount factor between any two periods in the future is $\delta$. With the structure of quasi-hyperbolic discounting, suppose that $\beta=0.9$ and $\delta=0.99$. In the current period $t$, a reward of 10 that starts to materialize in period $t+3$ is preferred to a reward of 9 that starts at period $t+2\left(\beta \delta^{3} 10 \succ \beta \delta^{2} 9\right)$. When period $t+2$ arrives, this preference is reversed by the same individual as $9 \succ \beta \delta 10$. In other words, quasi-hyperbolic time preferences involve problems of self control ${ }^{6}$. Following O’Donoghue and Rabin (1999), we distinguish between sophisticated and naive individuals, where the former are aware of their self-control problems and the latter are not. A naive hyperbolic individual believes incorrectly that in the future she will behave as an exponential individual with $\beta=1$. Sophisticated individuals predict the behaviour of their future selves perfectly.

The job seeker chooses a level of search effort and a wage acceptance policy to solve the optimisation programme:

$$
\max _{s_{t} \in[0,1]} b-c\left(s_{t}\right)+\beta \delta\left[s_{t} E_{F}\left\{\max \left(V_{t+1}^{E}(w), V_{t+1}^{U}\right)\right\}+\left(1-s_{t}\right) V_{t+1}^{U}\right]
$$


where $b$ :is the benefits of unemployment, $c\left(s_{t}\right)$ : is the cost of search, $\beta:$ is short-run patience, $\delta:$ is long-run patience, $s_{t}$ : is the probability of receiving an employment offer in period $t, V_{t+1}^{E}(w)$ : is the continuation payoff of employment if the job seeker accepts a wage offer, and $V_{t+1}^{U}$ : is the continuation payoff of unemployment if the job seeker rejects a wage offer or does not receive a wage offer.

Let us now study the various assumptions that can be derived from the resolution of this model. These assumptions are used to determine the nature of the correlation between impatience and the search effort, between impatience and the reservation wage, and between impatience and the exit rate from unemployment. These assumptions will be tested empirically using French data from the European Household Panel Survey.

- Hypothesis 1. At equilibrium, there is a negative correlation between impatience and the search effort. Search effort is strictly decreasing with short-run impatience $(1-\beta)$ and longrun impatience $(1-\delta)$ for exponential $(\beta=1)$ and hyperbolic job seekers $(\beta \prec 1)$ with the same long-run discount factor $\delta$.

- Hypothesis 2. For exponential and hyperbolic agent, the reservation wage is strictly decreasing with long-run impatience $(1-\delta)$. The reservation wage is strictly decreasing with short-run impatience $(1-\beta)$ for sophisticated hyperbolic job seekers with $\beta \prec 1$ and is independent of short-run impatience $(1-\beta)$ for naive job seekers.

- Hypothesis 3. The exit rate from unemployment is strictly decreasing with short-run impatience for naive job seekers. For sophisticated job seekers, the exit rate is also strictly decreasing with short-run impatience if

$$
\frac{\partial E[W / W \geq x]}{\partial x} \leq \frac{1}{1-\beta} \text { at } x=w^{*}
$$


Given that short-run impatience affects the search effort directly, increasing $(1-\beta)$ tends to decrease the exit rate from unemployment through the decrease in search effort.

- Hypothesis 4. Taking into account that there is a probability that a job seeker who finds work will be laid off, the exit rate from unemployment is increasing with long-run impatience $(1-\delta)$ if $\delta$ is quite high (close to 1) and for plausible values of the layoff probability $^{7}$. Given that long-run impatience affects the reservation wage directly, increasing $(1-\delta)$ tends to increase the exit rate from unemployment through the decrease in the reservation wage.

The main objective of the empirical study reported in this paper is to test the predictions of this model using French longitudinal data. The results of this empirical part will help us to identify the nature of the time preferences of the job seekers in the sample and to remove the uncertainty of the effect of impatience on exit rate from unemployment. If job seekers have exponential preferences $(\beta=1)$, impatience increases the exit rate from unemployment and if they have hyperbolic preferences $(\beta \leq 1)$, impatience decreases the exit rate from unemployment. Knowing the type of time preferences that job seekers have can help to guide the formulation of labour market policies to reduce unemployment.

\section{Data and non-parametric analysis}

The data used comes from the French sample of the European Household Panel Survey conducted by Eurostat, and covers eight waves of study from 1994 to 2001 (Table 1). This longitudinal survey can be used to trace the history of job seekers on the labour market retrospectively. It provides complete information on the characteristics of individual job seekers and household structures. 
Table 1. Descriptive Statistics

\begin{tabular}{|c|c|c|c|}
\hline Variables & Mean & Standard Errors & Observations \\
\hline Age & & & \\
\hline Age & 34.280 & 11.5328 & 2161 \\
\hline Class $1[<25]$ & 0.2693 & 0.4437 & 2161 \\
\hline Class 2 [25-35] & 0.2915 & 0.4545 & 2161 \\
\hline Class $3[35-45]$ & 0.2008 & 0.4007 & 2161 \\
\hline Class $4[45-55]$ & 0.1864 & 0.3895 & 2161 \\
\hline Class $5[55+]$ & 0.0518 & 0.2217 & \\
\hline Gender & & & \\
\hline Men & 0.4595 & 0.4984 & 2161 \\
\hline Marital Status & & & \\
\hline Married & 0.3937 & 0.4887 & 2161 \\
\hline Skill Level & & & \\
\hline No education & 0.1170 & 0.3215 & 2161 \\
\hline General education & 0.1591 & 0.3659 & 2161 \\
\hline Short Technical education & 0.3012 & 0.4589 & 2161 \\
\hline Long Technical education & 0.0814 & 0.2735 & 2161 \\
\hline University degree & 0.1962 & 0.3972 & 2161 \\
\hline Region & & & \\
\hline Rural Town & 0.2697 & 0.4439 & 2161 \\
\hline$<20,000$ inhabitants & 0.1522 & 0.3593 & 2161 \\
\hline $20,000-100,000$ inhabitants & 0.1485 & 0.3557 & 2161 \\
\hline$>100,000$ inhabitants & 0.3109 & 0.4629 & 2161 \\
\hline Paris & 0.1184 & 0.3232 & 2161 \\
\hline Impatience measures & & & \\
\hline No Bank account & 0.4885 & 0.5000 & 2161 \\
\hline No Life insurance & 0.6500 & 0.4771 & 2161 \\
\hline Smoking & 0.2145 & 0.4106 & 2161 \\
\hline Consuming one's income and incurring debt & 0.0693 & 0.2541 & 2161 \\
\hline No Contribution to humanitarian associations & 0.7659 & 0.4236 & 2161 \\
\hline Other variables & & & \\
\hline Reservation wage & 6.5598 & 2.6742 & 2161 \\
\hline Number of search methods & 2.3678 & 0.7985 & 2161 \\
\hline Unemployed compensated (unemployment benefits) & 0.6598 & 0.4738 & 2161 \\
\hline Log (income per household member) & 8.0718 & 0.6204 & 2161 \\
\hline
\end{tabular}

The panel monitors, for each individual, the timing of unemployment spells in each wave. It provides complete information on the characteristics of individual job seekers and household structures. The incidence of unemployment spells by individuals and by observation creates a sample of 2161 observations. The analysis of individual spells of unemployment shows $68.84 \%$ complete spells. The number of individual spells of unemployment registered varies between one and 12; the average is 1.96 with the average length being 7.35 months. Job seekers who received unemployment benefits represent $65 \%$ of the sample. Women accounted for $54 \%$ of the sample. The average age for the whole sample is 34 years. While the share of graduates from higher education is close to $20 \%$, there is still a higher proportion of graduates from short-term technical education, such as the Certificate of Professional Aptitude or the Diploma of Professional Studies. The average hourly reservation 
wage is around 6.56 euros. Thirty-one percent of the sample live in a region with more than 100,000 inhabitants.

We now explain our choice of impatience measures. In the past, time preferences were often measured by experimental studies, in which people are asked to evaluate stylized intertemporal prospects that involve choice $\operatorname{tasks}^{8}$ (Cox and Oaxaca 1989, 1990). Impatient individuals prefer to receive immediate rewards and to avoid immediate costs in a way that our 'long-run selves' do not appreciate (O'Donoghue and Rabin, 1999). Conversely, patient individuals prefer activities that have immediate costs and delayed benefits. Does behaviour that privileges a present or shorter-term solution constitute proof that people have a preference for the present (impatience) or that they simply have an aversion to risk? It may prove difficult to differentiate between impatience and risk aversion completely, because the correlation between these two factors cannot be denied. Individuals who are strongly riskaverse are also very impatient (Anderhub and al., 2001). We collected information on the French data of the European Household Panel Survey in order to construct measures of impatience. Three assumptions were used in our empirical study: (i) impatience measures do not distinguish between short-run and long-run impatience; (ii) the discount rate does not change between the activities; and (iii) the level of impatience does not vary over time. Our measures may be imperfect proxies for impatience and they may pick out a number of other individual traits (e.g., tastes for leisure, or risk preferences) in addition to time preferences. An explanation of why individuals prefer to consume today rather than tomorrow must appeal to a more specific phenomenon, one's psychological nature. To improve the quality of our study, we attempted to control for these various factors in our choice of impatience measures. The proxies that we selected are as follows: 
Having a bank account: A simple model of saving behaviour predicts that individuals who are more patient delay consumption and accumulate more wealth. Therefore, they are more likely to have some type of bank account. $51.15 \%$ of individuals in the sample had a bank account. Contribution to humanitarian associations: This type of behaviour characterizes patient individuals. Contributing to associations for the benefit of society, rather than for personal gain, indicates patience. This type of individual has long-term vision and seeks to prepare better conditions for future generations. Individuals who do not contribute to humanitarian associations are strongly represented in the sample (76\%).

Smoking $^{9}$ : This activity is pleasurable at the time of consumption but detrimental to health in the long term. An impatient individual (smoker) will be satisfied with the short-term benefit without assigning importance to the long-term disadvantage. Daily smokers represent $21.45 \%$ of the sample.

Consuming one's income and incurring debt: Having difficulty in keeping to one's budget and incurring debt due to consumption can be related to impatience. An impatient person thinks less at the moment of purchase, and exposes him- or herself to exceeding the limits of his or her budget. Such individuals represent only $7 \%$ of the sample.

Life insurance: The individuals who subscribe to a life insurance policy have a preference for the long term and show a weak preference for the present. Individuals who do not have life insurance represent $65 \%$ of the sample.

In order to homogenize impatience measures, we transformed them into reduced centred values. This process of standardizing data has the advantage of homogenizing data without changing the results of various statistical analyses. The analysis of correlation between the impatience measures shows that among 10 pairwise correlations, nine have a positive sign and are statistically different from zero (Table 2). 
Table 2. Correlation of impatience measures

\begin{tabular}{|c|c|c|c|c|c||}
\hline \hline & No Bank account & No Life insurance & Smoking & $\begin{array}{c}\text { Consuming one's } \\
\text { income and } \\
\text { incurring debt }\end{array}$ & $\begin{array}{c}\text { No Contribution to } \\
\text { humanitarian } \\
\text { associations }\end{array}$ \\
\hline No Bank account & 1.000 & & & \\
\hline No Life insurance & $\begin{array}{c}0.2032 \\
(0.0000)\end{array}$ & 1.000 & & & \\
\hline Smoking & $\begin{array}{c}0.5853 \\
(0.0000)\end{array}$ & $\begin{array}{c}0.1677 \\
(0.0000)\end{array}$ & 1.000 & & \\
\hline $\begin{array}{c}0.1450 \\
(0.0000)\end{array}$ & $\begin{array}{c}0.0849 \\
(0.0001)\end{array}$ & $\begin{array}{c}0.1060 \\
(0.0000)\end{array}$ & 1.000 & \\
\hline $\begin{array}{c}\text { Consuming one's income and } \\
\text { incurring debt }\end{array}$ & $\begin{array}{c}0.0685 \\
(0.0015)\end{array}$ & $\begin{array}{c}0.0854 \\
(0.0001)\end{array}$ & $\begin{array}{c}0.0414 \\
(0.0541)\end{array}$ & 1.000 \\
\hline humanitarian associations & $(0.0000)$ & \multicolumn{3}{|c|}{} \\
\hline
\end{tabular}

To measure the quality of the measure, we used Cronbach's alpha coefficient. A statistical index varies between 0 and 1 , which is used to evaluate the homogeneity or consistency of an instrument. The value of Cronbach's alpha coefficient was 0.536, which reflects an average correlation between the measures of 0.06 . Both measures are very similar to those of Drago (2006) and Della Vigna and Paserman $(2005)^{10}$. We determined an aggregate measure of impatience with factor analysis by using the five standardized proxies describe above. Factor analysis aims at reducing a significant amount of information to a few large dimensions. It is a statistical method that is used to describe variability among observed variables $\left(x_{1}, x_{2}, \ldots, x_{n}\right)$ in terms of fewer unobserved variables called factors. The observed variables are modelled as linear combinations of a set of common factors $\left(F_{1}, \ldots, F_{Q}\right.$, with $\left.Q \prec P\right)$ and a unique factor $\left(Y_{P}\right)$ for each variable:

$$
X_{p}=a_{n_{1}} F_{1}+a_{n_{2}} F_{2}+\ldots+a_{n_{Q}} F_{Q}+u_{n} Y_{n} \quad(n=1,2, \ldots, N)
$$

We estimated a factor model via maximum likelihood (Harman 1976, ch.10) using the measures of impatience. The results are presented in Table 3. 
Table 3. Factor Analysis, Aggregate Measure of Impatience

\begin{tabular}{|c|c|c|c||}
\hline Impatience measures & Factor Loadings & Uniqueness & Score \\
\hline No Bank account & 0.1461 & 0.9786 & 0.0906 \\
\hline No Life insurance & 0.4151 & 0.7757 & 0.1502 \\
\hline Smoking & 0.2060 & 0.9401 & 0.0920 \\
\hline Consuming one's income and incurring debt & 0.1371 & 0.7179 & 0.3451 \\
\hline No Contribution to humanitarian associations & 0.1552 & 0.9425 & 0.1083 \\
\hline
\end{tabular}

We retained only one factor. For this factor, all factor loadings have positive signs. Our conjecture was that this factor is impatience. The score coefficient was used to create the aggregate measure of impatience, which is a weighted average of the individual variables. The measures that received the most weight are consuming one's income and incurring debt, and life insurance.

Given that the data set does not contain information on search intensity per se, we used the following search methods used by the job seeker to define a measure of search intensity: (1) registration at the public employment agency, (2) personal steps taken to find a job (searching through newspapers, word of mouth from friends and relatives, direct contact with possible employers, etc.), and (3) contact with the public employment agency and following a programme of individual support. The average number of methods used by each unemployed person is 2.36 .

The reservation wage is defined as the minimum wage below which an unemployed person refuses a job offer. The reservation wage is an important determinant of the probability that an unemployed person will exit unemployment. Nevertheless, direct information about the reservation wage is scarce ${ }^{11}$. However, having the reservation wage determined by the unemployed person him- or herself opens other possibilities. The way in which the French data of the European Household Panel Survey is collected includes asking the unemployed about the minimum hourly wage for which they would go to work. The unemployed are asked initially about the number of hours that they would like to work per week, then about the 
minimum wages that they would accept for the number of hours that they have just declared. The direct use of the answers to these questions raises difficulties about the sincerity of the statements (Feldstein and Poterba, 1984). However, a majority of previous studies have agreed to consider this type of response as relevant information on the behaviour of labour supply (Ridder and Gorter, 1986; Jones, 1988). Indeed, the distribution of the reservation wage seems to be consistent with the mean and variance observed in wages in France (Table 1). To supplement the descriptive analysis of the sample, survival rates in unemployment were estimated by means of a Kaplan-Meier estimation (Figure 1).

Figure 1. Kaplan-Meier estimator of the survival function in unemployment

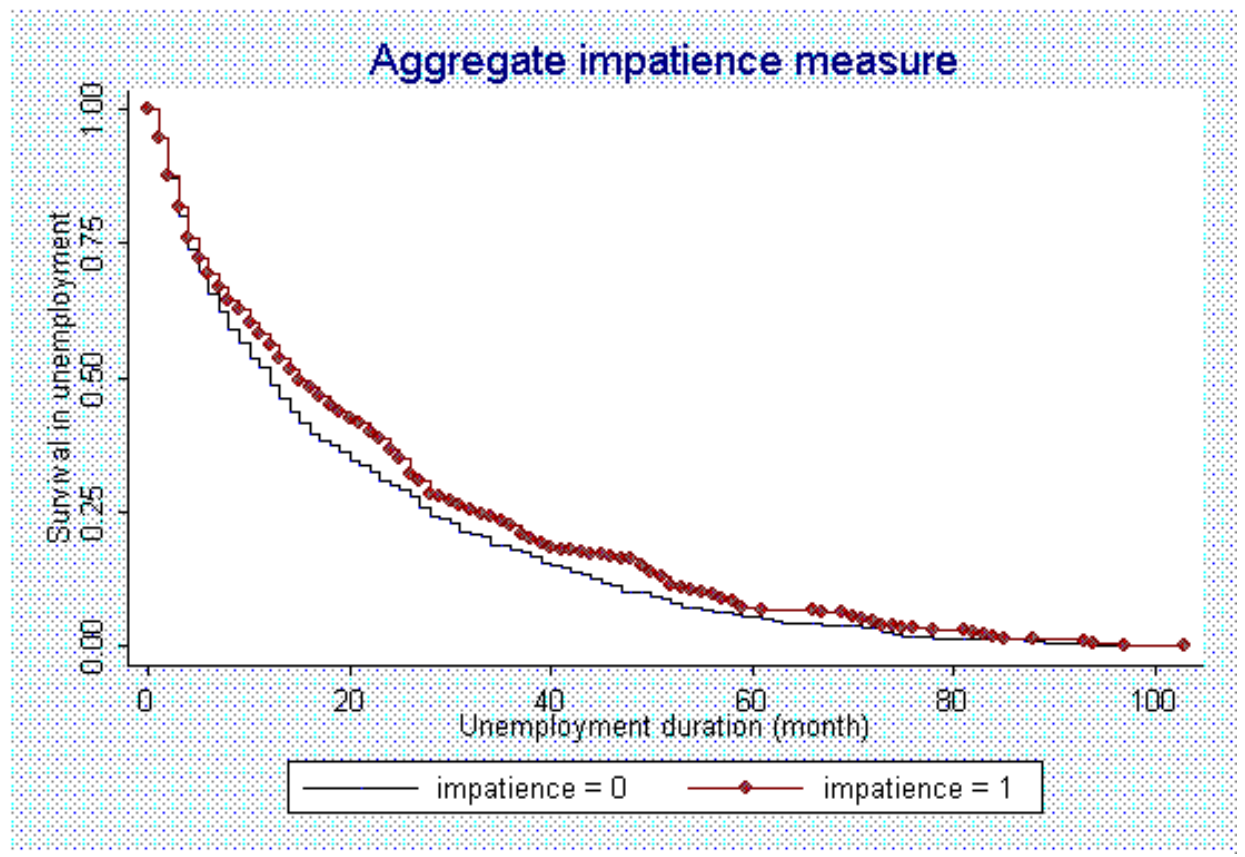

The aggregate impatience measure is continuous variable. We distinguished between job seekers with low impatience, characterized as unemployed patient (1st quartile), and job seekers with high impatience, characterized as unemployed impatient (bottom quartile). The results of this estimation enable us to compare the survival function in unemployment between patient (impatience $=0$ ) and impatient job seekers (impatience $=1$ ). We show that the survival curve for a patient job seeker is below that of an impatient job seeker. The non- 
parametric estimation (Kaplan-Meier) gives us an idea of the effect of impatience on survival function in unemployment: patient job seekers stay less in unemployment than impatient.

\section{Estimation}

At each period, the job seeker chooses his search effort and his reservation wages. These two variables determine the probability of exiting unemployment. As we saw in the theoretical model of Della Vigna and Paserman (2005), there is a correlation between job seekers' impatience and (a) their search effort, and (b) their reservation wages. The global effect of impatience on the exit rate from unemployment is unclear. The estimation results will enable us to determine the nature of the correlation between impatience and search effort, impatience and reservation wages, and impatience and exit rate from unemployment.

\subsection{Impatience and search effort}

We now determine the nature of the correlation between impatience and search intensity. The equation for search effort is as follows:

$$
\text { Intensity }_{i}=\alpha_{1}+\beta_{1}^{\prime} \mathrm{X}_{\mathrm{i}}+\gamma_{1}^{\prime}\left(\operatorname{IMP}_{i}\right)+\varepsilon_{i}
$$

where Intensity ${ }_{i}$ is search intensity, $X_{i}$ is the vector of explanatory variables, and $I M P_{i}$ is impatience measures. The econometric model that best fits this situation is the Poisson model as the dependent variable; the number of search methods is a non-negative integer ${ }^{12}$. For this estimation, we use socio-demographic variables: level of education, number of inhabitants in the region, household income per person, the reception of unemployment benefits, and impatience measures. For the search effort equation (4), we conduct two separate estimates. In the first estimation, we use impatience measures and in the second we use the aggregate impatience measure. Both estimates allow us to compare the results of the effect of impatience. The estimation results of the equation of search effort are reported in Table 4 
(columns 1 and 2, for the impatience measures and the aggregate impatience measure, respectively).

Not having a bank account, not having life insurance, and smoking have a significant and negative effect on search effort. Most of the impatience measures show a strong negative correlation between impatience and search effort. This result is confirmed by the second estimation using the aggregate impatience measure. These results confirm theoretical predictions; there is a negative correlation between impatience and search effort. The US data used by Della Vigna and Paserman (2005) shows that search effort is correlated negatively with impatience. For the other explanatory variables, age has a significant negative effect on search effort. Men tend to expend more effort on search than women. Receiving unemployment benefit has a significant and negative effect on search effort. Compensated individuals expend less effort on search than those who are not.

\subsection{Impatience and reservation wage}

The determination of the reservation wage requires comparing the long-term consequences of obtaining a certain wage with the wait to receive a better offer. In this case, contrary to the decision on the level of search effort, the variation of long-run impatience dominates the variation of short-run impatience. The equation for the reservation wage is as follows:

$$
\log \left(W_{i}\right)=\alpha_{2}+\beta_{2}^{\prime} \mathrm{X}_{\mathrm{i}}+\gamma_{2}^{\prime}\left(\operatorname{IMP} P_{i}\right)+\mu_{i},
$$

where $\log \left(W_{i}\right)$ is the $\log$ of reservation wage, $X_{i}$ is the vector of explanatory variables, and $I M P_{i}$ is the impatience measures. Using the Ordinary Least Square method (OLS), we determine, on the one hand, the effect of impatience on the reservation wage and, on the other hand, the effect of other variables on the reservation wage.

The results of this estimation (Table 4, columns 3 and 4) help to test the correlation between impatience and the reservation wage ${ }^{13}$. The first estimate (column 3) uses the 
impatience measures, while the second estimate (column 4) uses the aggregate impatience measure. Not having a bank account, not having life insurance, or not subscribing to humanitarian associations has a significant and negative effect on the reservation wage. Most of the impatience measures show a strong negative correlation between impatience and the reservation wage. This result is confirmed by the sign and the significance of the coefficient of the aggregate impatience measure (column 4). This confirms previous results and shows that workers who are more impatient set a lower reservation wage. We can now confirm the theoretical predictions; there is a negative correlation between impatience and the reservation wage. Data from the US used by Della Vigna and Paserman (2005), in an analysis that does not include the control variables (age, education, marital status, etc.), shows that the reservation wage is correlated negatively with impatience. This correlation was not significant after including the control variables. Our result is different and could be due to the possibility that the measures of impatience are reflecting other dimensions of unobserved heterogeneity (for example, heterogeneity in human capital).

The income per household member and age, independently, had a significant and positive effect on the reservation wage. The effect on the reservation wage increases as the age of the individual increases. Men specify a higher reservation wage than women. When they are married, both men and women lower their reservation wage. It is also noted that the reservation wage grows steadily with the level of education. Individuals who had higher education specified a higher reservation wage than individuals with a lower standard of education (taken as a reference). Individuals who live in rural areas or cities that have fewer than 100,000 inhabitants tend to specify a lower reservation wage than those who live in the Paris region. 


\subsection{Search effort, reservation wage, and exit rate from unemployment}

To determine the nature of the correlation between (a) search effort and the exit rate from unemployment, and (b) between reservation wage and the exit rate, a semi-parametric Cox proportional hazard model was used (Cox, 1972). This type of model allows all the standard determinants to be controlled for. It also allows duration dependence, which is the pure effect of the duration of unemployment on the probability of moving to employment, to be controlled for. The hazard model utilizes data on the sequence, timing, and the state that an individual is in; the probability of the type of exit is a function of time. This is referred to as the hazard rate or function. The hazard rate is the dependent variable, and the relationship between this rate and a variety of observed and unobserved variables is modelled. The hazard model has been widely used in biomedical and social science research, by Cox (1972), Kalbfleish and Prentice (1980), and Heckman and Singer (1984). As before, let Ti be a nonnegative random variable that denoted the duration of unemployment for individual $i$. We now define $h_{i}(t)$, the hazard at time $t$ for individual $i$, as follows:

$$
h_{i}(t)=\lim _{\Delta t \rightarrow 0} \frac{\operatorname{Pr}\left\{t \leq T_{i} \leq t+\Delta t / T_{i} \geq t\right\}}{\Delta t}
$$

Thus, this equation gives the probability that a job seeker will exit from unemployment between $t$ and $t+\Delta t$, under the condition that the job seeker had not already died by time $t$. In order to estimate the exit rate from unemployment and the effects of independent variables on this, we need to specify the functional form of the hazard model. The most widely used specifications are the accelerated time model and the Cox proportional hazard model. According to the Cox proportional hazard model (Cox, 1972), covariates have a multiplicative relationship with the hazard function (the proportionality assumption), which causes them to shift the hazard function up or downward. Therefore, covariates do not affect the duration of 
an activity directly ${ }^{14}$. Given that we are studying the effect of explanatory variables on the exit from unemployment, a Cox proportional hazard model is used. It is specified by

$$
h\left(t_{i} \mid X\right)=h_{0}\left(t_{i}\right) \exp \left(-x_{i} \beta\right)
$$

where $t_{i}$ is the elapsed duration of unemployment for individual $i ; h\left(t_{i} / X\right)$ denotes the hazard rate conditional on a vector of covariates $X ; h_{0}(t)$ denotes the baseline hazard function measuring the effects of the time that has passed since becoming unemployed on the probability of moving to another state; and $x_{i} \beta$ denotes the covariates and parameter estimates for the exit rate.

The results of the determinants of the exit rate of unemployment are given in Table 4 (column 5 and 6). The first estimate (column 5) presents the correlation between the reservation wage and the exit rate, while the second estimate (column 6) identifies the correlation between search effort and the exit rate, using a Cox proportional hazard model.

The search effort has a significant effect on the exit rate from unemployment. Individuals who expend more search effort exit from unemployment after a shorter time (Result 1). The reservation wage does not have a significant effect on the exit rate from unemployment (Result 2). Taken together, Results 1 and 2 show us that the effect of the search effort dominates the effect of the reservation wage: this implies that individuals who are more impatient expend less effort on search and so may exit from unemployment more slowly. Given that the effect of search effort dominates the level of reservation wage, we may conclude that the job seekers in our sample exhibit hyperbolic, rather than exponential, preferences. This last result shows that job seekers are more concerned by short-term impatience rather than by long-term impatience. Given this result, job-search programmes should reduce the short-term costs of research, which are immediately supported. Job seekers who belong to age group 2 [25-35 years] and group $5[55 ;+]$ remain unemployed for longer 
than job seekers who belong to age group 1 [ $<25$ years] (taken as a reference). The probability of men exiting unemployment is higher than that of women. We also note that job seekers who are married exit unemployment more slowly. Job seekers who have a university degree exit unemployment more quickly than individuals who are uneducated (taken as a reference). Job seekers who live in areas with a population of 20,000 to 100,000 are unemployed for shorter periods than those who live in the Paris region.

\section{Conclusion}

This paper contributes to the literature on hyperbolic discounting. A second contribution of this paper is to compare our results on French data with the results of Della Vigna and Paserman on U.S. data. This comparison gave us an idea about the time preferences type of unemployed in both countries and policies that can be applied to reduce unemployment. Within a model that views search effort as endogenous, increasing impatience implies a reduction in search efforts and therefore reduces the exit rate from unemployment. At the same time, impatience increases the reservation wage and it reduces the exit rate from unemployment. The overall effect of impatience on the exit rate is unclear and requires a comparison of the relative strengths of effects. The effect of search effort dominates the reservation wage if job seekers have hyperbolic preferences, while the reservation wage dominates search effort if job seekers have exponential preferences. Put differently, the exit rate increases if the job seekers have hyperbolic preferences and decreases if they have exponential preferences. In the empirical test, we found that impatience measures are correlated negatively with the reservation wage and search effort. The results of the Cox proportional hazard model show that search effort has a positive effect on the exit rate from unemployment, whereas the reservation wage does not have a significant effect. This final result informs us about the nature of job seekers' time preferences. Given that the effect of 
search effort dominates the effect of reservation wages, we may conclude that the job seekers exhibit hyperbolic, rather than exponential discount.

The effectiveness of policies whose objective is to reduce unemployment depends on the nature of the time preferences of the unemployed. Hyperbolic preferences affect problems associated with job search and policies aimed at reducing unemployment. Hyperbolic agents are particularly sensitive to the immediate costs of job search (including contacting employers to obtain an interview, calling relatives, etc.). To reduce the immediate costs of the search to the job seeker, public employment services in France should follow up the unemployed more efficiently so that they may obtain information that will help them to reduce the costs of job search. France is exceptional because there are many heterogeneous actors and authorities of different status, which the job seeker must consult several times to stay informed. The creation of 'houses of employment' could provide an opportunity to establish some basic principles for active policies to allow fluidity between unemployment and reemployment. This can be achieved by the effective reduction of the costs borne by the unemployed. Interactive kiosks could also be set up, where job seekers can submit their curriculum vitae and schedule interviews at low cost. This administrative simplification for job seekers is now available in nearly all Western countries. However, such simplification is exceptionally slow in France. 


\section{Appendix}

Table 4: Search effort, Reservation wage, and Exit rate from unemployment

\begin{tabular}{|c|c|c|c|c|c|c|}
\hline & \multicolumn{2}{|c|}{ Search effort } & \multicolumn{2}{|c|}{ Reservation wage } & \multicolumn{2}{|c|}{ Exit rate from unemployment } \\
\hline & Column 1 & Column 2 & Column 3 & Column 4 & Column 5 & Column 6 \\
\hline Reservation wage & - & - & - & - & $\begin{array}{l}\mathbf{- 0 . 0 6 7 3} \\
\quad(0.0465)\end{array}$ & - \\
\hline Search effort & - & - & - & - & & $\begin{array}{l}\mathbf{0 . 1 5 6 6} \\
(0.0458)\end{array}$ \\
\hline Aggregate impatience measure & - & $\begin{array}{r}-0.0239^{*} \\
(0.0132) \\
\end{array}$ & - & $\begin{array}{r}-0.0231^{* *} \\
(0.0117) \\
\end{array}$ & $\begin{array}{r}-0.0627^{* * *} \\
(0.0122) \\
\end{array}$ & $\begin{array}{r}-0.0836^{* * *} \\
(0.0109) \\
\end{array}$ \\
\hline \multicolumn{7}{|l|}{ Impatience measures } \\
\hline No Bank account & $\begin{array}{r}-0.0795^{* * *} \\
(0.0114)\end{array}$ & - & $\begin{array}{l}-0.0530^{* * *} \\
(0.0219)\end{array}$ & - & - & - \\
\hline No Life insurance & $\begin{array}{l}-0.0438^{*} \\
(0.0232)\end{array}$ & - & $\begin{array}{l}-0.0586^{* *} \\
(0.0227)\end{array}$ & - & - & - \\
\hline Smoking & $\begin{array}{l}-0.0709^{* * * *} \\
(0.0126)\end{array}$ & - & $\begin{array}{l}0.0631 \\
(0.0450)\end{array}$ & - & - & - \\
\hline $\begin{array}{l}\text { Consuming one's income and } \\
\text { incurring debt }\end{array}$ & $\begin{array}{l}0.0278 \\
\quad(0.0750)\end{array}$ & - & $\begin{array}{l}0.0021 \\
(0.0420)\end{array}$ & - & - & - \\
\hline $\begin{array}{l}\text { No contribution to humanitarian } \\
\text { associations }\end{array}$ & $\begin{array}{r}-0.0240 \\
\quad(0.0447)\end{array}$ & - & $\begin{array}{r}-0.0912^{* * *} \\
(0.0249)\end{array}$ & - & - & - \\
\hline $\begin{array}{l}\text { Log (income per household } \\
\text { member) }\end{array}$ & $\begin{array}{l}-0.0366 \\
(0.0342)\end{array}$ & $\begin{array}{r}-0.0468 \\
(0.0335)\end{array}$ & $\begin{array}{l}0.1162^{* * *} \\
(0.0180)\end{array}$ & $\begin{array}{l}0.1195^{* * *} \\
(0.0179)\end{array}$ & $\begin{array}{l}-0.1260^{* *} \\
(0.0642)\end{array}$ & $\begin{array}{l}-0.1234^{*} \\
(0.0725)\end{array}$ \\
\hline Unemployment benefits & $\begin{array}{r}-0.1260^{* *} \\
(0.0435)\end{array}$ & $\begin{array}{r}-0.1239^{* *} \\
(0.0434)\end{array}$ & $\begin{array}{l}0.0285 \\
\quad(0.0224)\end{array}$ & $\begin{array}{l}0.0265 \\
(0.0235)\end{array}$ & $\begin{array}{l}-0.0474^{* * *} \\
(0.0121)\end{array}$ & $\begin{array}{r}-0.0469^{* * *} \\
(0.0119)\end{array}$ \\
\hline \multicolumn{7}{|l|}{ Age } \\
\hline Class $1[<25]$ & Ref & Ref & Ref & Ref & Ref & Ref \\
\hline Class 2 [25-35] & $\begin{array}{l}-0.0667 \\
\quad(0.0531)\end{array}$ & $\begin{array}{r}-0.0647^{* * *} \\
(0.0253)\end{array}$ & $\begin{array}{l}0.0745^{* *} \\
\quad(0.0274)\end{array}$ & $\begin{array}{l}0.0703^{* *} \\
(0.0277)\end{array}$ & $\begin{array}{l}-0.3551^{* *} \\
\quad(0.0974)\end{array}$ & $\begin{array}{l}-0.3547^{* * *} \\
\quad(0.0967)\end{array}$ \\
\hline Class 3 [35-45] & $\begin{array}{r}-0.0301 \\
(0.0638)\end{array}$ & $\begin{array}{r}-0.1234^{* * *} \\
(0.0337)\end{array}$ & $\begin{array}{l}0.1353^{* * *} \\
(0.0310)\end{array}$ & $\begin{array}{l}0.1269^{* * * *} \\
(0.0335)\end{array}$ & $\begin{array}{l}-0.0886 \\
\quad(0.0725)\end{array}$ & $\begin{array}{l}-0.0718 \\
\quad(0.0727)\end{array}$ \\
\hline Class 4 [45-55] & $\begin{aligned}-0.1257^{*} \\
(0.0727)\end{aligned}$ & $\begin{array}{r}-0.1443^{* * *} \\
(0.0349)\end{array}$ & $\begin{array}{c}0.1970^{* * * *} \\
(0.0339)\end{array}$ & $\begin{array}{c}0.1821^{* * * *} \\
(0.0378)\end{array}$ & $\begin{array}{l}-0.1162 \\
(0.1105)\end{array}$ & $\begin{array}{c}-0.1019 \\
(0.1075)\end{array}$ \\
\hline Class $5[55+]$ & $\begin{array}{r}-0.2629^{* *} \\
(0.1052)\end{array}$ & $\begin{array}{r}-0.2570^{* * * *} \\
(0.0948)\end{array}$ & $\begin{array}{c}0.3158^{* * *} \\
(0.0491)\end{array}$ & $\begin{array}{l}0.3038^{* * * *} \\
(0.0516)\end{array}$ & $\begin{array}{c}-0.5666^{* * *} \\
(0.1206)\end{array}$ & $\begin{array}{r}-0.5666^{* * *} \\
(0.1206)\end{array}$ \\
\hline \multicolumn{7}{|l|}{ Gender } \\
\hline Men & $\begin{array}{l}0.1169^{* * *} \\
(0.0399)\end{array}$ & $\begin{array}{l}0.1723^{* * *} \\
(0.0395)\end{array}$ & $\begin{array}{l}0.1604^{* * *} \\
(0.0200)\end{array}$ & $\begin{array}{l}0.1621^{* * * *} \\
(0.0205)\end{array}$ & $\begin{array}{l}0.3979^{* * *} \\
\quad(0.1373)\end{array}$ & $\begin{array}{l}0.3918^{* * *} \\
\quad(0.1389)\end{array}$ \\
\hline Women & Ref & Ref & Ref & Ref & Ref & Ref \\
\hline \multicolumn{7}{|l|}{ Marital Status } \\
\hline Married & $\begin{array}{l}-0.0273 \\
(0.0479)\end{array}$ & $\begin{array}{l}-0.0076 \\
\quad(0.0247)\end{array}$ & $\begin{array}{l}-0.0509^{*} \\
\quad(0.0285)\end{array}$ & $\begin{array}{l}-0.0521^{*} \\
(0.0284)\end{array}$ & $\begin{array}{l}-0.1360^{* *} \\
\quad(0.0642)\end{array}$ & $\begin{array}{r}-0.1373^{* *} \\
(0.0661)\end{array}$ \\
\hline Others & Ref & Ref & Ref & Ref & Ref & Ref \\
\hline \multicolumn{7}{|l|}{ Skill Level } \\
\hline No education & Ref & Ref & Ref & Ref & Ref & Ref \\
\hline General education & $\begin{array}{l}-0.0503 \\
\quad(0.0658)\end{array}$ & $\begin{array}{l}-0.0516 \\
\quad(0.0657)\end{array}$ & $\begin{array}{l}-0.0299 \\
(0.0337)\end{array}$ & $\begin{array}{r}-0.0307 \\
(0.0331)\end{array}$ & $\begin{array}{l}-0.0423 \\
\quad(0.0662)\end{array}$ & $\begin{array}{r}-0.0431 \\
(0.0606)\end{array}$ \\
\hline Short Technical education & $\begin{array}{l}-0.0328 \\
\quad(0.0515)\end{array}$ & $\begin{array}{l}-0.0385 \\
(0.0517)\end{array}$ & $\begin{array}{l}-0.0392 \\
\quad(0.0272)\end{array}$ & $\begin{array}{c}-0.0314 \\
(0.0269)\end{array}$ & $\begin{array}{l}0.0153 \\
\quad(0.0736)\end{array}$ & $\begin{array}{l}0.0138 \\
(0.0752)\end{array}$ \\
\hline Long Technical education & $\begin{aligned}-0.0170 \\
\quad(0.0515)\end{aligned}$ & $\begin{array}{l}-0.0185 \\
\quad(0.0515)\end{array}$ & $\begin{array}{l}0.0213 \\
\quad(0.0408)\end{array}$ & $\begin{array}{l}0.0237 \\
(0.0398)\end{array}$ & $\begin{array}{l}-0.0591 \\
\quad(0.0856)\end{array}$ & $\begin{array}{r}-0.0591 \\
(0.0870)\end{array}$ \\
\hline University degree & $\begin{array}{c}-0.0328 \\
(0.0574)\end{array}$ & $\begin{array}{c}0.0327 \\
(0.0573)\end{array}$ & $\begin{array}{c}0.1495^{\text {**** }} \\
(0.0298)\end{array}$ & $\begin{array}{c}0.1520^{* * * *} \\
(0.0281)\end{array}$ & $\begin{array}{l}0.1729^{* *} \\
(0.0831)\end{array}$ & $\begin{array}{l}0.1774^{* *} \\
(0.0881)\end{array}$ \\
\hline \multicolumn{7}{|l|}{ Region } \\
\hline Rural Town & $\begin{array}{l}-0.0143 \\
(0.0565)\end{array}$ & $\begin{array}{l}0.0113 \\
(0.0566)\end{array}$ & $\begin{array}{l}-0.0399^{*} \\
(0.0242)\end{array}$ & $\begin{array}{l}-0.0744^{* *} \\
(0.0363)\end{array}$ & $\begin{array}{l}0.0143 \\
\quad(0.0705)\end{array}$ & $\begin{array}{l}0.0149 \\
\quad(0.0739)\end{array}$ \\
\hline$<20,000$ inhabitants & $\begin{array}{l}0.0013 \\
(0.0756)\end{array}$ & $\begin{array}{c}-0.0015 \\
(0.0758)\end{array}$ & $\begin{array}{c}-0.04906^{*} \\
(0.0294)\end{array}$ & $\begin{array}{r}-0.0836^{* *} \\
(0.0399)\end{array}$ & $\begin{array}{l}0.0293 \\
\quad(0.0611)\end{array}$ & $\begin{array}{l}0.0231 \\
\quad(0.0692)\end{array}$ \\
\hline $20,000-100,000$ inhabitants & $\begin{array}{l}0.0138 \\
\quad(0.0364)\end{array}$ & $\begin{array}{l}0.0136 \\
(0.0363)\end{array}$ & $\begin{array}{c}-0.07099^{* *} \\
(0.0293)\end{array}$ & $\begin{array}{l}-0.1078^{* *} \\
(0.0397)\end{array}$ & $\begin{array}{l}0.2002^{* * *} \\
(0.0533)\end{array}$ & $\begin{array}{l}0.1925^{* * *} \\
(0.0518)\end{array}$ \\
\hline$>100,000$ inhabitants & $\begin{array}{l}-0.0175 \\
(0.0668)\end{array}$ & $\begin{array}{c}-0.0172 \\
(0.0671)\end{array}$ & $\begin{array}{c}-0.0506 \\
(0.0296)\end{array}$ & $\begin{array}{c}-0.0461 \\
(0.0349)\end{array}$ & $\begin{array}{l}0.0387 \\
(0.0790)\end{array}$ & $\begin{array}{l}0.0368 \\
(0.0785)\end{array}$ \\
\hline Paris & Ref & Ref & Ref & Ref & Ref & Ref \\
\hline Constant & $\begin{array}{l}1.1642^{\text {**** }} \\
(0.3081)\end{array}$ & $\begin{array}{l}1.1084^{* * * *} \\
(0.2901)\end{array}$ & $\begin{array}{c}3.6792^{\text {**** }} \\
(0.0504)\end{array}$ & $\begin{array}{r}3.6357^{* * * *} \\
(0.0483)\end{array}$ & - & - \\
\hline Log-Likelihood & -1843.8174 & -1844.1065 & - & - & -4822.081 & -4815.1527 \\
\hline Numbers of observation & 2161 & 2161 & 2161 & 2161 & 2161 & 2161 \\
\hline
\end{tabular}

Note. Standard errors in parentheses, *: significant at the 0.1 level, **: significant at the 0.5 level, ***: significant at the 0.01 level. 


\section{Notes}

${ }^{1}$ An individual with high time discounting is assumed to be impatient, while an individual with low time discounting is assumed to be patient.

2 This inconsistency is presented by the following situation. When confronted with the choice between two payments that are close in time, for example, $\$ 10$ today or $\$ 11$ tomorrow, many agents prefer $\$ 10$ today and thus demonstrate a remarkably high discount rate. However, given a longer time scale, most agents choose to take $\$ 11$ in 101 days instead of $\$ 10$ in 100 days, even though the period between the payments is still just one day.

${ }^{3}$ For more details, see Della Vigna and Paserman (2005) pp. 531-544.

${ }^{4}$ It is common in the literature to view search effort as endogenous (Burdett and Mortensen, 1978; Mortensen 1986; Albrecht, Holmlund, and Lang 1991)

${ }^{5}$ Quasi-hyperbolic discounting is an approximation of hyperbolic time preferences (Phelps and Pollack, 1968; Laibson, 1997). Such preferences imply a lower discount factor when the delay horizon is short (short-run impatience) than when the delay horizon is long (long-run impatience) and generate problems of self-control and time-inconsistency in a simple fashion.

${ }^{6}$ Many empirical regularities regarding consumption (Angeletos and al., 2001; Laibson, 1997), drug addiction (Gruber and Koszegi, 2001), and unemployed worker behaviour (Paserman, 2004), among others, are explained better in terms of quasi-hyperbolic preferences than in terms of time-consistent preferences.

${ }^{7}$ For more details, see Della Vigna and Paserman (2005) pp.538-540

${ }^{8}$ Respondents' answers to the question "Which would you prefer: $\$ 100$ today or $\$ 150$ one year from today?

${ }^{9}$ An individual was treated as a smoker if he declared himself to be a daily smoker and not a casual smoker.

${ }^{10}$ Glaeser, Laibson, Scheinkman and Soutter (2000) show that there is a low correlation between measures of an individual trait. The correlation can be reduced by a measurement error in the choice of impatience measures, but this should not alter the sign.

11 There is little empirical data to confirm or disconfirm this theoretical concept. In the absence of direct observation, study that seeks to evaluate the effect of the reservation wage on the duration of unemployment supposes that the relation, predicted by the theory of job search, which relates it to the level of the unemployment benefits, the arrival rate of offers, and the distribution of the wages offered, is well checked. The reservation wage can then be estimated by using information available on these variables.

${ }^{12}$ We estimated the equation of search effort using the binomial negative model. According to the coefficient of sur-dispersion (alpha), we retain the Poisson model.

${ }^{13}$ We use the same list of the variables used in the estimation in the equation for search effort.

${ }^{14}$ In contrast, the accelerated time model (Cox and Oakes, 1984) assumes that covariates act multiplicatively on time rather than on the hazard function. Covariates, therefore, increase or decrease the time spent on an activity.

\section{References}

Albrecht J.W., Holmlund B., and Lang H. (1991) 'Comparative statics in dynamic programming models with an application to job search', Journal of Economic Dynamics and Control 15(4): 755-69.

Anderhub V., Güth W., Gneezy U., and Sonsino D. (2001) 'On the Interaction of Risk and Time Preferences: An Experimental Study’, German Economic Review 2(3): 239-253.

Angeletos G.M., Laibson D., Tobacman J., Repetto A. and Weinberg S. (2001) 'The Hyperbolic Consumption Model: Calibration, Simulation, and Empirical Evaluation', Journal of Economic Perspectives 15(3): 47-68.

Becker Gary S. and Mulligan Casey B. (1997) 'The endogenous determination of time preference', Quarterly Journal of Economics 112(3): 729-758.

Burdett K., and Mortensen D.T. (1978) 'Labor supply under uncertainty', Research in Labor Economics 2:10957.

Burdett K. and Ondrich J.I. (1985) 'How changes in labour demand affect unemployed workers', Journal of Labour Economics 3(1): 1-10.

Chapman G.B. (1996) 'Temporal discounting and utility for health and money', Journal of Experimental Psychology: Learning, Memory, and Cognition 22(3): 771-791. 
Cox J.C. and Oaxaca R.L. (1989) 'Laboratory experiments with a finite horizon job search model', Journal of Risk and Uncertainty 2: 301-330.

Cox J.C. and Oaxaca R.L. (1992) 'Direct Tests of the Reservation Wage Property', The Economic Journal 102(415): 1423-1432.

Della Vigna S. and Paserman D. (2005) 'Job Search and Impatience', Journal of Labour Economics 23(3): 527588.

Drago F. (2006) 'Career Consequences of Hyperbolic Time Preferences', IZA Discussion Paper (2113).

Fang H. and Silverman D. (2004) 'Measuring Time Inconsistency: Evidence from Work-Welfare Decisions in the NLSY', Working Paper. Department of Economics, Yale University.

Feldstein M. and Poterba J. (1984) 'Unemployment Insurance and Reservation Wage', Journal of Public Economics, 23(1): 141-167.

Glaeser E.L., Laibson D.I., Scheinkman J.A., and Soutter C.L. (2000) 'Measuring Trust', Quarterly Journal of Economics 115(3): 811-846.

Gruber J. and Koszegi B. (2001) 'Is Addition ”Rational”? Theory and Evidence', Quarterly Journal of Economics, 116(4): 1261-1305

Gorter D. and Gorter C. (1993) 'The Relation between Unemployment Benefits, the Reservation Wage and Search Theory', Oxford Bulletin of Economics and Statistics 55(2): 199-214.

Harman, Harry H. (1976) 'Modern factor analysis', Chicago: University of Chicago Press.

Harris C. and Laibson D. (2001) 'Dynamic Choices of Hyperbolic Consumers', Econometrica 69(4): 935-957.

Heckman J.J. and Robb R.J (1985) 'Alternative Methods for Evaluating the Impact of Interventions : an Overview', Journal of Econometrics 30(1): 239-267.

Heckman J.J. and Singer B. (1984) 'A Method of Minimizing the Distributional Impact in Econometric Models for Duration Data', Econometrica 52(2): 271-320.

Jones S. (1988) 'The Relationship between Unemployment Spells and Reservation Wages as a Test of Search Theory', The Quarterly Journal of Economics 103(4): 741-765.

Kalbfleisch J.D., Prentice R.L. (1980) 'The Statistical Analysis of Failure Time Data', Wiley Series in Probability and Statistics, New York.

Kirby K. (1997) 'Bidding on the future: Evidence against normative discounting of delayed rewards', Journal of Experimental Psychology : General 126(1): 54-70.

Laibson D. (1997) 'Golden Eggs and Hyperbolic Discounting', Quarterly Journal of Economics 112(2): 443477 .

Lancaster T. (1979) 'Econometric Methods for the Duration of Unemployment', Econometrica 47(4): 939-956.

Mischel W., Shoda Y., and Rodriguez M.L. (1989) 'Delay of gratification in children', Science, 244 (4907): 933938.

Mortensen, Dale T. (1986) 'Job Search and Labor Market Analysis', Handbook of Labor Economics 2: 849-919.

Myerson J. and Green L. (1995) 'Discounting of delayed rewards : Models of individual choice', Journal of Experimental Analysis of Behavior 64(3): 263-276.

O’Donoghue T. and Rabin M. (1999) 'Doing it Now or Later', American Economic Review 89(1): 103-124.

Paserman, D. (2004) 'Job Search and Hyperbolic Discounting: Structural Estimation and Policy Evaluation', IZA Discussion paper (997).

Pender J.L. (1996) 'Discount rates and credit markets: Theory and evidence from rural India', Journal of Development Economics 50(2): 185-199.

Phelps E.S. and Pollak R. (1968) 'On Second-Best National Saving and Game-Equilibrium Growth', The Review of Economic Studies 35(2): 185-199.

Ridder G. and Gorter K. (1986) 'Unemployment Benefits and Search Behaviour: an Empirical Investigation', Cornell University, New York, and University of Amsterdam.

Samuelson S. (1937) 'A note on measurement of utility', The Review of Economic Studies, 4(2): 155-161.

Strotz, R.H. (1956) 'Myopia and inconsistency in dynamic utility maximization', The Review of Economic Studies 23(3): 165-180.

Cox, D.R. (1972) 'Regression models and life tables', Journal of Royal Statistical Society 34(2): 248275.

Cox, D.R. and Oakes D. (1988) 'Analysis of Survival Data', Monographs on Statistics and Applied Probability Chapman \& Hall, London (201). 